\title{
Discussion about Plant Landscape Configuration in the Construction of Urban Rainwater Gardens
}

\author{
Shuzhen Zou ${ }^{1, a *}$, Yu Zeng ${ }^{1}$, Wanjun Duan ${ }^{2}$, Ran $\mathrm{Li}^{1}$ \\ ${ }^{1}$ Jiangxi Science \& Technology Normal University, Jiangxi, Nanchang, China \\ ${ }^{2}$ Jiangxi Ceramic and Art Institute, Jiangxi, Jingdezhen, China 333000 \\ azsz2928@qq.com;
}

Keywords: Nanchang, rainwater garden, plant

\begin{abstract}
As a main force of rainwater garden, plant has the functions of degrading waste water, conserving water source and increasing water circulation. Through the investigation and research about indigenous plants in wetlands, this article discusses the plant configuration in rainwater gardens in Nanchang and how to utilize plants to build an artsy "rainwater bank", thereby putting emphasis on endowing rainwater gardens with relatively high landscape value.
\end{abstract}

\section{Introduction}

Also being called bioretention area, rainwater garden refers to the low-lying areas planted with trees or shrubs in garden green fields and covered by barks or ground cover plants, which can replenish underground water by retaining rainwater and sinking it and reduce the flood peaks of rainstorm's ground runoffs. Besides, it can reduce pollution via absorption, degradation, ion exchange and evaporation. Therefore, it is a kind of ecological and sustainable facility for rainfall flood control and rainwater utilization.

Functions of plants in rainwater garden: landscape function via visual perception of plant communities, reducing runoffs, reducing pollution via absorption, degradation, ion exchange, evaporation and other processes, providing inhabitance for other organisms, improving small climatic environment. Rainwater garden is mainly comprised of 4 parts: cover layer, vegetation, planting soil layer, artificial packing layer and gravel layer. A layer of sand layer or geotechnical cloth can be laid between the packing layer and gravel layer. According to specific requirements of different rainwater gardens, there are 2 methods, namely, seepage-proofing and non-seepage-proofing. If having the requirement of water storage or discharge into other water body, water-collection perforated pipes can be embedded in the gravel layer.

\section{Selection principles of plants in rainwater gardens}

\subsection{Indigenous tree species with strong stress resistance, drought and flood tolerance preferred}

The selection of plants in rainwater garden should firstly consider their anti-pollution, anti-drought and anti-flood abilities. In urban areas, the conditions for plant living are limited, so it is relatively stable to select local tree species with strong stress resistance for rainwater garden. Secondly, there are 2 design methods for anti-seep rainwater gardens, that is, seepage-proofing and non-seepage-proofing. For the latter design, the water amount in rainwater garden varies with water-rising stage and drought period. The rainfall in Nanchang is abundant, but not even in different seasons, that is to say, Nanchang has apparent rainy season and drought season. The rainy

\footnotetext{
* Shuzhen Zou, Professor of Jiangxi Science \& Technology Normal University, main research direction: environmental art.; Yu Zeng, Lecturer of Jiangxi Science \& Technology Normal University, main research direction: environmental art.; Wanjun Duan,Teacher of Jiangxi Ceramic and Art Institute , main research direction: environmental art; Ran Li, Student of Jiangxi Science \& Technology Normal University, main research direction: environmental art..
} 
season mainly falls on April to June, the total rainfall in these 3 months accounting for $51 \%$ of the annual rainfall, especially, May and June contributing most. The latter one falls on October to December, its rainfall only taking up 9.7\% of the annual amount. While in the period from August to October, the evaporation amount is equal to about 2.79 times of that of rainfall, causing the lowest soil water content all the year round. Therefore, plant configuration in rainwater garden needs to consider drought period and water-rising period and the species with anti-drought and anti-flood abilities should be selected with priority.

\subsection{Plants with strong root stock and degradation ability}

Rainwater contains a large amount of pollutants which are harmful to water and land ecology system, such as, acids, toxic metal, organics, Nitrogen and Phosphor material and so on, maybe resulting in the pollution of ground water body. Rainfall runoffs on vehicle lanes may contain metal, rubber, fuel and other pollutant material due to vehicle wearing. Some plants have extremely strong pollution degradation capacity or the capacity to absorb heavy metal. Therefore, when selecting plant species used in rainwater garden, those with strong degradation capacity should take precedence.

\subsection{Plants with strong landscape appreciation functions}

Rainwater garden is part of landscape green field. There are precedent cases showing artistry and strong landscape effect. For instance, plant species with strong ornamental value or better collective appreciation effects should be selected as much as possible. In addition, plant classification should be taken for those being able to adapt to the living conditions of rainwater garden.

Herbaceous plants for flower appreciation: Consolida ajacis, Iris tectorum Maxim, Acorus calamus L, Nelumbo nucifera, Nymphaea tetragona Georgi, Lythrum salicaria L, Monochoria korsakowii, Nelumbo nucifera Gaertn, Iris pseudacorus L, Ammannia multiflora Roxb.

Herbaceous plants for leaf appreciation: Thalia dealbata Fraser, Scirpus validus Vahl, Cyperus alternifolius, Alisma plantago-aquatica Linn, Alternanthera philoxeroides (Mart.) Griseb, Polygonum orientale Linn, Phragmites australias Trin, SagittariatrifoliaL.Var.Angusti-folia(Sieb.)Kitag, Hydrocotyle vulgaris L, Typha orientalis Presl, Pontederia cordata L, Canna glauca L, Polygonum hydropiper, Cyperus alternifolius, Thalia dealbata, Hedychium coronarium Koen, Miscanthus sinensis Andress 'Zebrinus', Cortaderia selloana, Alocasia macrorrhiza, Ceratophyllum demersum L.

Ligneous plants for appreciation: Metasequoia glyptostroboides, Taxodium ascendens. Brongn, Taxodium distichum (L.), Glyptostrobus pensilis (Staunt.) Koch, S.babylonica, Pterocarya stenoptera C. DC, Hibiscus mutabilis Linn.

\subsection{Plants with high biomass and strong anti-mosquito ability while being able to provide inhabitance for beneficial organisms}

Apart from purifying water body and improving landscape environment, plants also have the function of enriching biodiversity, for instance, bird-attracting plants can bring vitality for water body; plants with anti-mosquito ability can enhance the human friendliness of water body. Water-tolerant wet arbors planted in juncture areas of rainwater garden and land can stabilize water body boundaries and prevent rainwater brushing.

Bird-attracting plants: Cinnamomum camphora (L.) Presl, Osmamthus fragrans, Euonymus japonicus Thunb(not trimmed), Photinia glabra, Chaenomeles speciose, Phragmites australias Trin, Taxodium ascendens. Brongn, Platycladus orientalis (L.) Franco, Sabina chinensis (L.) Ant, Juniperus sibirica Burgsd, Sabina chinensis (L.) Ant. cv. Kaizuca, Cedrus deodara (Roxb.) G. Don, Magnolia Grandiflora, Ligustrum lucidum Ait., Cerasus sp, Cerasus pseudocerasus G. Don, Ginkgoaceae, Liquidambar formosana Hance, Liriodendron chinense (Hemsl.) Sarg, Eriobotrya japonica (Thunb.) Lindl, Sapium sebiferum (L.) Roxb, Salix matsudana Koidz.

Anti-mosquito plants: Mentha haplocalyx Briq, Artemisia argyi H. Lév. \& Vaniot, Tagetes 
erecta L, Pelargonium domesticum Bailey, Rosmarinus officinalis, Ocimum basilicum.

\subsection{Plant selection as follows respectively based on two foundation treatment methods of rainwater gardens, namely, seepage-proofing and non-seepage-proofing:}

Seepage-proofing treatment: taking into consideration the applicable principles of water-rising stage and drought period, and the thickness to protect seepage-proofing layer and soil layer, aquatic plants with shallow root system should be selected as much as possible, such as, Nymphaea tetragona Georgi, Nelumbo nucifera, Monochoria korsakowii, Myriophyllum verticillatum L. and so on.

Non-seepage-proofing treatment: as for plant selection, pay attention to choose more species with both anti-drought and anti-flood capacity, such as, Metasequoia glyptostroboides, Taxodium ascendens. Brongn, Taxodium distichum (L.), Pterocarya stenoptera C. DC, Nerium indicum Mill, Salix babylonica, pinus elliottii, Pilea peperomioides Diels, Myriophyllum verticillatum L. and so on.

\section{Plant configuration on rainwater gardens}

\subsection{Configuration principles}

\subsubsection{Practicality principle}

Regarding waterfront plant communities in rainwater garden, the species with strong environment adaptation ability and better ecological profit should be introduced properly so as to establish stable plant community as soon as possible and improve the ecological function of rainwater garden; the selected aquatic plant community should have anti-pollution capacity and own the function of purifying water body in order to realize the improvement of wetland environment.

\subsubsection{Stability principle}

Plants in rainwater garden should be mainly focused on indigenous ones because this kind of configuration can ensure the long-term stability of plant community. To realize the sustainable development of plant community in rainwater garden, the species with better economic profit should be selected.

\subsubsection{Landscape coherence principle}

Rainwater garden should also select plants with seasonal changes, abundant colors and relatively high observability and combine them properly. Landscape art should be applied in their configuration so as to bring the landscape aesthetics of ambient environment up to a higher level via plants in rainwater garden.

\subsection{Configuration basis of plant communities in rainwater gardens in Nanchang}

Wetland plants include hygrophytes and aquatic plants, the latter species can also divided into emergent aquatic plants, floating plants and submerged plants. The wetland plant community includes hygrophyte community, emergent aquatic plant community, floating plant community and submerged plant community. When building these communities, plant ones from local nature and indigenous species should be selected with priority considering the stability of community structure so as to reduce the negative influences brought by future uncontrollable factors. Therefore, the status quo of mature wetland plant community in Jiangxi province is also an important basis for the plant configuration in rainwater gardens of Nanchang, its main pursuant indexes are as follows: the first is the outcome of mature wetland plant community succession, the second is the community constitution of indigenous plants.

On the basis of having certain understanding about present wetland plant community in Nanchang, there are two other referable basis for the plant community configuration in rainwater gardens of Nanchang, one is plants' anti-pollution and environment purification abilities, the other is plants' landscape appreciation value. When configuring plant community of rainwater garden, the 
above-mentioned 4 basis should be considered comprehensively.

\section{The rainwater gardens in Nanchang mainly have the following 4 landscape forms according to local environmental characteristics and selection principles of plant species in rainwater gardens and after plant landscape configuration optimization:}

\subsection{Eco-filtration grassed waterway}

Eco-filtration grassed waterways have the functions of filtering and transporting urban rainwater, meanwhile enhancing infiltration and reducing rainwater recharge. The side slopes of ecological grassed waterway should choose herbaceous plants having strong vegetation restoration and anti-brushing abilities. At the bottom, the soaked anti-drought species should be selected. Plant configuration of grassed waterway is generally comprised of side slope plants and bottom plants, which is rarely applied in Nanchang. There are some designed topography in green fields which is very suitable for making eco-filtration grassed waterway and being made into drought river, thus not having the good function of ecological purification and filtration.

For example, figure one below shows some place in Fenghuangzhou Citizen Park, the side slope plants include Polygonum hydropiper L, Oenothera biennis L, Verbena bonariensis, Ilex crenata cv.Convexa Makino, Ophiopogon jaburan Argenteivittatus, Miscanthus sinensis cv, which creates a good plant landscape effect. At the bottom, pebbles are utilized to cover open ditch drainage, which collects ground runoffs and directly discharge into rainwater pipes, thus not having the function of rainwater garden. In the figure two, the topography is also very suitable for making eco-filtration grassed waterways. However, there is no plant at the bottom, pebbles are already covered by the soil brushed down, resulting in a bad landscape effect, only having the function of collecting ground runoffs and not having eco-filtration effect. If some anti-brushing plants are added into current side slope ones, such as, Zoysia japonica Steud, Reineckia carnea (Andr.) Kunth, O.japonicus(L. f.)Ker-Gawl, Trifolium repens L, while some anti-soaking plants are used at the bottom, for instance, Hydrocotyle vulgaris L., Iris tectorum Maxim, Myriophyllum verticillatum L, Canna indica, Acorus calamus L, Phragmites australias Trin, Polygonum hydropiper L, soil and gravel infiltration layer is applied under the vegetation layer instead of open ditch drainage, the functions of eco-filtration grassed waterway can be realized.

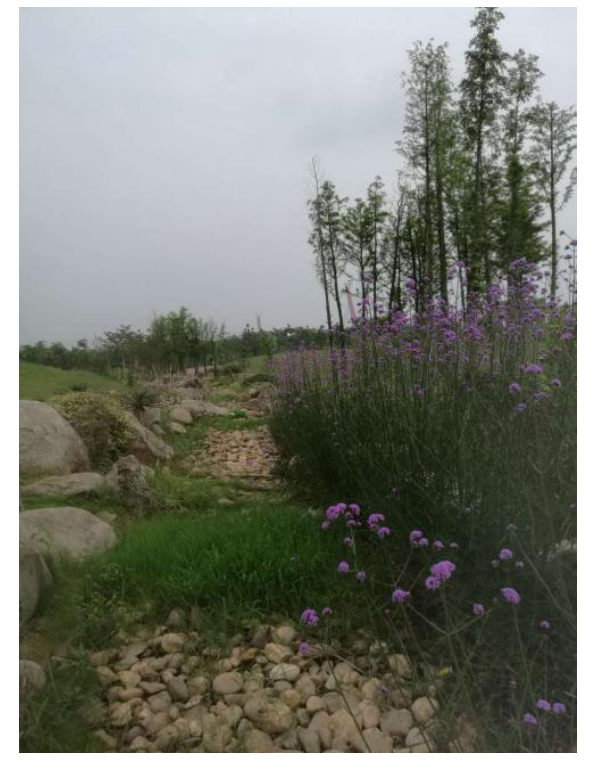

Figure 1: Grassed waterway in Fenghuangzhou Citizen Park 


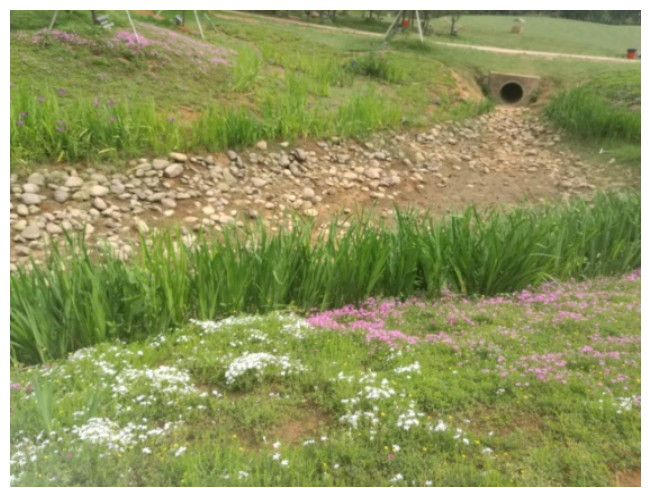

Figure 2: Ecological grassed waterway in Fenghuanggou

\subsection{Rainwater low-lying land}

Water storage is only done in rainstorm period, meanwhile, rainwater flow management can be taken in this period. In order to enhance rainwater infiltration and reduce rainwater recharge, plants with anti-drought and anti-flood abilities should be matched properly. The form of rainwater low-lying land in rainwater garden is very concentrative, normally appearing in several wetland parks. For example, in the rainwater low-lying land in Fish-boat Cove as shown in figure 3, the plant configuration is Pilea peperomioides Diels + Myriophyllum verticillatum L + Phragmites australias Trin + Thalia dealbata Fraser, which form a stable plant community with reasonable plant matching and being able to withstand certain drought and flood test. However, in other green fields, low-lying land often appears in Lawn micro-topography, which doesn't combine with the plant configuration method in rainwater low-lying land, consequently not having the function of rainwater garden. For instance, figure 4 shows low-lying land in the greed fields affiliated to some Nanchang university, its plant configuration is a mixed turf with Zoysia matrella and Trifolium repens L. When configuring plants for rainwater low-lying land, the following several configuration can be referenced: Myriophyllum verticillatum L - Acorus calamus L + Nerium indicum Mill Pterocarya hupehensis; Phragmites australias Trin - Canna indica L + Hibiscus mutabilis Linn Metasequoia glyptostroboides; Arundo donax - Iris wilsonii C. H. Wright - Acorus calamus L + S.babylonica - Taxodium ascendens. Brongn.

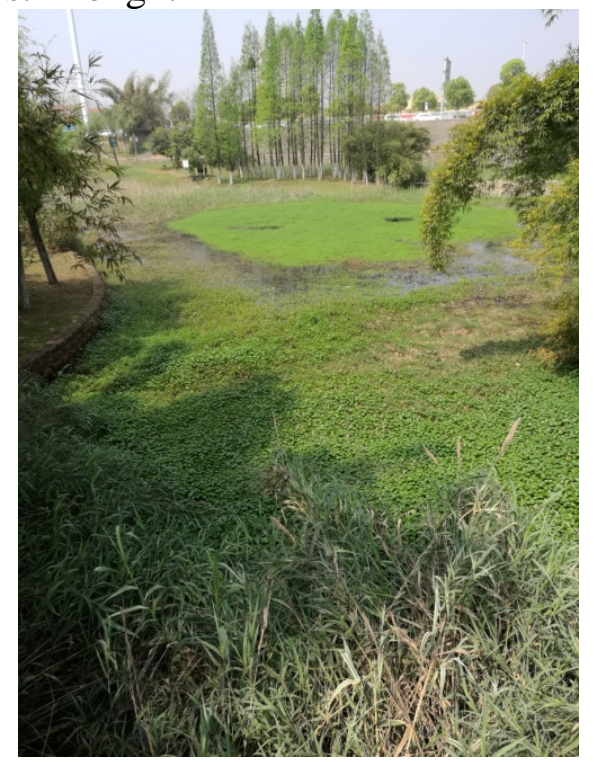

Figure 3: Rainwater low-lying land in Fish-boat Cove 


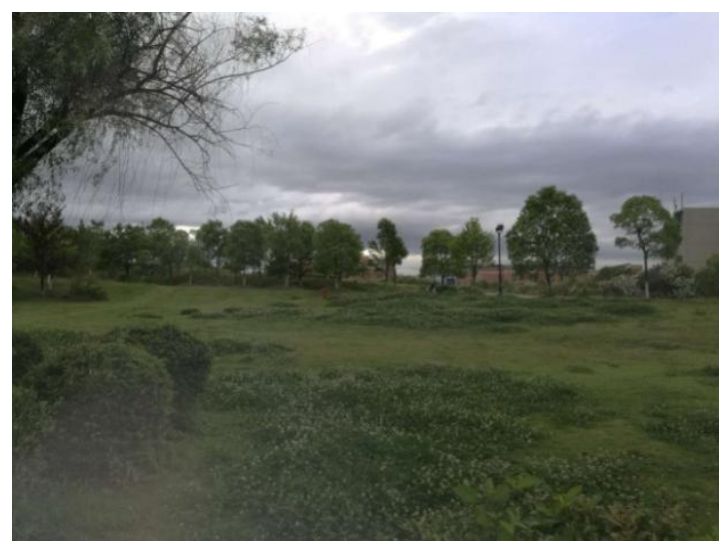

Figure 4: Rainwater low-lying land in some Nanchang university

\subsection{Artificial wetland}

Artificial wetland can further reduce the elapse of sediments and nutrients, reduce organism, chemical oxygen demand and water pollutants, provide important biological inhabitance, enhance infiltration and reduce rainwater recharge. Presently, the plant configuration of artificial wetland in Nanchang is intermingled with good and bad ones. In wetland parks, plant configuration is rich in their species and proper in their matching. While in the artificial wetland near the Ganjiang River, the plant configuration is relatively simple. To make vegetation buffer strip along river banks realize its good ecological profit, it is of great importance to set its width and configure the inside plant community. The artificial plant strips along river banks have incomparable buffering function, corridor function, bank-protecting function, soil erosion and non-point pollution prevention functions, so they are worthy paying attention to. The following artificial wetland configuration along river banks can be referenced: Hosta plantaginea Aschers - Typha orientalis Presl - Thalia dealbata Fraser + Pterocarya stenoptera C. DC - Hibiscus mutabilis Linn; Sagittaria sagittifolia Consolida ajacis (L.) Schur - Cyperus alternifolius + S.alba - PopulusL.

\subsection{Landscape lake}

Landscape lake is the main measure to realize rainwater flow control during rainstorm period, which can reduce suspended sediments, provide important biological inhabitance and enhance infiltration. The lakeside vegetation can impact the nutrition circulation of water and land ecology system while plant root system can withstand the erosion of lake water and ground runoffs, so a kind of buffer strip with transition property is formed between these two systems, which can give play to and stabilize the ecological functions of adjacent systems. The landscape lake in Nanchang mainly utilized artificial revetments, which is covered with cement and rock blocks, consequently losing the functions of rainwater garden and ecological landscape, this phenomenon is worthy of reflection by relevant departments. Some plant configuration cases in landscape lake are as follows: Pinus contorta Douglas ex Loudon + pinus elliottii - Acer palmatum Thunb + Nelumbo nucifera Euryale ferox Salisb. ex Konig et Sims - Nymphaea tetragona Georgi; Liriodendron chinense $\times$ tulipifera - Chimonanthus praecox(linn.)Link + Gardenia jasminoides Ellis + Thalia dealbata Fraser + Hydrilla verticillata - Ceratophyllaceae - Myriophyllum verticillatum L; Bischofia polycarpa + Sapium sebiferum (L.) Roxb - Photinia serrulata + Phragmites australias Trin - Thalia dealbata Fraser - :Consolida ajacis (L.) Schur.

\section{Conclusions}

Reasonable plant configuration in rainwater gardens has a positive effect on controlling water body pollution, conserving water source, maintaining water and soil and protecting biodiversity. Its stability, anti-pollution capacity, anti-drought and anti-flood characteristics are of great significance for rainwater gardens, which needs long-term experimental exploration and time verification. As 
well as keeping rainwater gardens' landscape function, we should try out best to make them create maximum ecological profit in urban areas.

\section{Acknowledgement}

Fund project: 2014 Jiangxi “the $12^{\text {th }}$ Five-year Plan" project about social sciences(14YS19); 2015 Jiangxi college research project about humanistic and social science(YS1525)

\section{References}

[1] Climatic Resources in Nanchang, Zhao Shusen, Liu Ziqing, Jiangxi Science, June 1990, Volume 8, Issue 2.

[2] Research about Rainfall Runoff Pollution Process in Nanchang Urban Areas and its Control Measures, Wang Yalei 2008

[3] Research about Plant Selection and Configuration based on LID Technology, Huang Wanmei 2015

[4] Functions and Management of Riparian Zones, Zhang Jianchun, Journal of Water and Soil Conservation, 2001, 15(6): 951-954

[5] Lake Eutrophication Control and Management Techniques, Jin Xiangchan, Beijing: Chemical Industry Press, 2001,56 